\title{
Choline chloride vs choline ionic liquids for starch thermoplasticization
}

\author{
Paul Decaen ${ }^{\mathrm{a}, \mathrm{e}}$, Agnès Rolland-Sabatée,e,f ${ }^{\mathrm{b}, \mathrm{f}}$, Sophie Guilois ${ }^{\mathrm{b}, \mathrm{e}}$, Vanessa Jury ${ }^{\mathrm{c}, \mathrm{e}}$, Nadine Allanic ${ }^{\mathrm{d}, \mathrm{e}}$, \\ Gaël Colomines $^{\mathrm{d}, \mathrm{e}}$, Denis Lourdin ${ }^{\mathrm{b}, \mathrm{e}}$, Eric Leroy ${ }^{\mathrm{a}, \mathrm{e}, *}$ \\ a UBL, CNRS, GEPEA, UMR 6144, CRTT, 37, Boulevard de l'Université, 44606, St Nazaire cedex, France \\ ${ }^{\mathrm{b}}$ UR1268 Biopolymères Interactions Assemblages, INRA, F-44300, Nantes, France \\ c UBL, ONIRIS, CNRS, GEPEA, UMR 6144, Rue de la Géraudière, CS 82225, 44322, Nantes cedex 3, France \\ d UBL, IUT de Nantes, CNRS, GEPEA, UMR 6144, OPERP, 2 Avenue du professeur Jean Rouxel, BP 539, 44475, Carquefou, France \\ e IBSM, Rue de la Géraudière, BP 71627, 44316 Nantes cedex 3, France \\ ${ }^{\mathrm{f}}$ UMR408 Sécurité et Qualité des Produits d'Origine Végétale, INRA, Université Avignon, F-84000, Avignon, France
}

\section{A B S T R A C T}

Keywords:

Starch

Plasticizer

Ionic liquids

Choline

Extrusion

\begin{abstract}
Native starch containing $12 \%$ water was melt processed in presence of $23 \%$ of various plasticizers at $120{ }^{\circ} \mathrm{C}$, either by simple compression molding or by extrusion using a laboratory scale microcompounder. Glycerol, a typical starch plasticizer, was used as a reference and compared to three choline salts: raw choline chloride (which is a solid in dry state with a melting point above $300{ }^{\circ} \mathrm{C}$ ), and two ionic liquids synthesized from this precursor (choline acetate and choline lactate, liquids below $100{ }^{\circ} \mathrm{C}$ ). These ionic plasticizers were shown to allow a more efficient melting of native starch in both processes. The investigation of macromolecular structure changes during processing shows that this efficiency can be ascribed to a starch chain scission mechanism, resulting in lower specific mechanical energy input need for starch thermoplasticization compared to glycerol plasticized starch. Compared to the synthesized ionic liquids, raw commercial choline chloride leads to a good compromise between limited chain scission, and final water uptake and thermomechanical properties.
\end{abstract}

\section{Introduction}

Starch is a widely available natural polymer. It is present in the form of semi-crystalline granules in plants and tubers. Starch granules contain linear (amylose) and branched (amylopectin) glucose biosynthesized polymers (Buleon, Colonna, Planchot, \& Ball, 1998). This raw material can be transformed by thermomechanical processes such as extrusion, in order to obtain thermoplastic starch (TPS) for various non food applications (Halley et al., 2008). However, the efficiency of thermomechanical processing and the final performances highly depend on moisture. During processing, the presence of water molecules decreases the melting temperature of starch granules (typically around $130{ }^{\circ} \mathrm{C}$ for a water content of $18-20 \%$ ) allowing the formation of a continuous polymer melt (Barron, Della Valle, Colonna, \& Vergnes, 2002). A minimum specific mechanical energy (SME) is required during extrusion (typically $100 \mathrm{~J} \mathrm{~g}^{-1}$ ) for the complete destructuration of native starch granules (Barron, Bouchet, Della Valle, Gallant, \& Planchot, 2001).

The thermomechanical properties of TPS also sensitive to moisture content. Water acts as an efficient plasticizer. Since water content depends on environmental relative humidity $(\mathrm{RH})$, this results in strong variations of the glass transition temperature $\left(\mathrm{T}_{\mathrm{g}}\right)$. Typically, a variation of $10{ }^{\circ} \mathrm{C}$ of $\mathrm{T}_{\mathrm{g}}$ can be observed for a $1 \%$ variation of $\mathrm{RH}$, in the range $20<\mathrm{RH}<80 \%$ (Lourdin, Coignard, Bizot, \& Colonna, 1997). The use of various non-volatile plasticizers to limit this effect has been widely investigated in the 1990's, allowing to adjust $T_{g}$ at a given $\mathrm{RH}$. (Lourdin et al., 1997). Beside polyols (glycerol, sorbitol, poly-ethylene glycol ...), other molecules have been used. This includes polar molecules such as urea, but also organic salts such as sodium carboxylates (lactate, citrate, tartrate, gluconate ...) (Fleche, Gosset, \& Lambla, 1996; Lourdin et al., 1997; Salmon, 1993). Starch was successfully extruded in presence all of these salts, water and/or polyols. However, sodium lactate showed the more efficient $\mathrm{T}_{\mathrm{g}}$ depressing effect (Salmon, 1993).

The use of such "salty" plasticizers for starch processing recently regained attention since the beginning of the present decade, taking advantage of the development of Room Temperature Ionic Liquids (RTILs) () (Bendaoud \& Chalamet, 2013; Colomines, Decaen, Lourdin, \& Leroy, 2016; Sankri et al., 2010; Wang, Zhang, Liu, \& He, 2009; Xie et al., 2014, 2015; Zdanowicz and Spychaj, 2011; Zhang et al., 2016) acents (DES) (Abbott et al., 2014; Abbott \& Ballantyne, 2011; Abbott, Ballantyne, Conde, Ryder, \& Wise, 2012; Leroy, Decaen et al., 2012; Ramesh, Shanti, \& Morris, 2012; Zdanowicz,

\footnotetext{
* Corresponding author at: UBL, CNRS, GEPEA, UMR 6144, CRTT, 37, Boulevard de l'Université, 44606, St Nazaire cedex, France.

E-mail address: eric.leroy@univ-nantes.fr (E. Leroy).
} 
Spychaj, \& Maka, 2016).

These two families of salty liquids have been successfully used in combination with water for the extrusion of starch (Abbott et al., 2014; Sankri et al., 2010). Promising effects on TPS thermomechanical properties were observed: low $\mathrm{T}_{\mathrm{g}}$ values (leading to a rubbery behavior at room temperature) (Sankri et al., 2010) and a limitation of starch recrystallization during aging (Sankri et al., 2010; Zhang et al., 2016). In blends and composites, the ionic plasticizers also allowed the compatibilization between starch and hydrophobic polymers (Leroy, Jacquet, Coativy, Reguerre, \& Lourdin, 2012; Liu, Qi, Zhang, Xu, \& Guo, 2015) or natural fibers (Abbott, Conde, Davis, \& Wise, 2012). The ionic conductivity resulting from the presence of RTILs and DESs also allowed the development of TPS solid polymer electrolytes (Ramesh et al., 2012; Wang et al., 2009).

Among the various ionic plasticizers tested, the choline based RTILs and DES are particularly interesting for their low toxicity and biodegradability (Colomines et al., 2016; Fukaya, Iizuka, Sekikawa, \& Ohno, 2007; Petkovic et al., 2010; Radosevic et al., 2015). This is mainly due to the intrinsically low toxicity of their precursor choline chloride, albeit the anion structure can also plays an important role (Petkovic et al., 2010). This component of vitamin B4 is actually biocompatible and widely used for animal feed. The thermoplasticization of starch by choline chloride by compression molding in presence of moisture has been described in literature (Abbott, 2009; Zdanowicz \& Spychaj, 2011). In the present work, we compare its influence on both compression molding and extrusion, to that of glycerol and two choline based ionic liquids (choline acetate and choline lactate). The structure and properties of the TPS obtained are also discussed.

\section{Experimental}

\subsection{Raw materials and synthesis of ionic liquids}

Regular corn starch (amylopectin/amylose ratio: 70/30) was purchased from Tate \& Lyle (Meritena 100), with an initial moisture content of $12 \%$. Glycerol. Potassium acetate [K] [Ace] and choline chloride ([Chol][Cl]) were purchased from Sigma-Aldrich. L-lactic acid [H][Lac] was purchased from Panreac and potassium hydroxide from LabOnline. Absolute ethanol was obtained from Alcogroup. They were all of analytical grade and were used without further purification.

The syntheses and complete characterization of ionic liquids were described in details in a previous article (Colomines et al., 2016). Briefly, the synthesis of Choline acetate [Chol][Ace] was done by ion exchange: [Chol][Cl] $(0.2 \mathrm{~mol})$ and potassium acetate $(0.2 \mathrm{~mol})$ were separately dissolved in $200 \mathrm{~mL}$ and in $800 \mathrm{~mL}$ absolute ethanol, respectively. Potassium acetate solution was added to the stirred [Chol] [Cl] solution. A white precipitate of potassium chloride was formed and removed by filtration after the solution was stirred for $1 \mathrm{~h}$ at room temperature. Ethanol was evaporated under vacuum. The compound obtained was the ionic liquid choline acetate [Chol][Ace]. The potassium chloride obtained was dried at $100{ }^{\circ} \mathrm{C}$ for $24 \mathrm{~h}$ and then heated at $750{ }^{\circ} \mathrm{C}$ to eliminate organic compounds in order to estimate the reaction yield.

In contrast, the synthesis of choline lactate [Chol][Lac] was done using the acid-base method: On the one hand, choline hydroxide ([Chol] $[\mathrm{OH}]$ ) was prepared according to the ion exchange method. Potassium hydroxide $(0.1 \mathrm{~mol})$ and $[\mathrm{Chol}][\mathrm{Cl}](0.1 \mathrm{~mol})$ were dissolved in $800 \mathrm{~mL}$ and in $200 \mathrm{~mL}$ absolute ethanol, respectively. Hydroxide solution was added to a stirred [Chol] $[\mathrm{Cl}]$ solution. The white precipitate was removed by filtration after stirring for $1 \mathrm{~h}$ at room temperature. On the other hand, L-lactic acid $(0.1 \mathrm{~mol})$ was dissolved in ethanol $(50 \mathrm{~mL})$. The L-lactic acid solution was added to the hydroxide solution. The solution was stirred at room temperature for $1 \mathrm{~h}$. Ethanol was evaporated under vacuum. The compound obtained was the ionic liquid choline lactate [Chol][Lac].

After synthesis, ionic liquids were hermetically packaged and stored at $4{ }^{\circ} \mathrm{C}$ without further purification. Their structures were confirmed by NMR (Colomines et al., 2016), their purity characterized: they both contain $2.5 \mathrm{wt} \%$ of $\mathrm{NaCl}$ or $\mathrm{KCl}$ residuals, and less than $8 \mathrm{wt} \%$ of residual volatile impurities (Colomines et al., 2016). The main volatile impurity was ethanol (from synthesis). The possible presence of water as secondary impurity could not be quantified by TGA since both volatile compounds evaporate at close temperature ranges (Colomines et al., 2016).

When stored at $4{ }^{\circ} \mathrm{C}$, [Chol] [Lac] remained liquid, while [Chol] [Ace] was subject to crystallization. A melting temperature $\mathrm{T}_{\mathrm{m}}=51{ }^{\circ} \mathrm{C}$ was measured (Colomines et al., 2016), which is slightly lower than that of pure [Chol] [Ace] according to Sigma-Aldrich chart $\left(80-85{ }^{\circ} \mathrm{C}\right)$. This difference may be ascribed to ethanol and water impurities.

\subsection{Starch thermoplasticization processes}

Thermoplastic starch (TPS) samples were prepared by thermomechanical transformation of native starch in presence of the four plasticizers: Glycerol, [Chol][Ace], [Chol][Lac] and [Chol][Cl]. The same processing conditions were also tested with the precursors of anionic moiety of the two ionic liquids: [Na][Ace] and [H][Lac]. The thermoplasticization of starch was studied in presence of water since it was previously shown that [Chol][Cl] cannot plasticize dry starch (Zdanowicz \& Spychaj, 2011). Native starch powder (12\% water) was premixed with $23 \%$ (dry basis (d.b.)) of plasticizer (or precursor) in a mortar just before processing. Note that the water initially present in the plasticizers may slightly increase the total water content in these premix.

Two thermomechanical processes were used: a simple compression molding $\left(120^{\circ} \mathrm{C}, 20 \mathrm{MPa}, 5 \mathrm{~min}\right)$, and a laboratory scale microcompounder allowing the simulation of twin-screw extrusion (Minilab, HAAKE, Thermo Haake). This conical twin screw system equipped with a backflow channel allows the mixing of batches of $8 \mathrm{~g}$ of mixture during a controlled residence time before extrusion. This allowed using the same time/temperature conditions as in compression molding $\left(120^{\circ} \mathrm{C}, 5 \mathrm{~min}\right.$ ), but under shear (the screw's speed was set to $100 \mathrm{rpm}$ ). The torque signal was recorded and used to calculate the Specific Mechanical Energy (SME) $\left(\mathrm{J} \mathrm{g}^{-1}\right)$ :

$S M E=\int_{0}^{t} \frac{2 \pi \cdot n \cdot C}{60 \cdot M} d t$

Where $\mathrm{C}$ is the torque signal at mixing time $\mathrm{t}, \mathrm{n}$ is the screw speed (rpm) and $\mathrm{M}$ is the loaded mass.

After processing, all samples were stored at $25{ }^{\circ} \mathrm{C}$ under a controlled relative humidity of $57 \%$ (using a reference saturated sodium bromide salt solution) before characterizations.

In addition, water thermoplasticized amorphous starch samples (without non volatile plasticizer) were prepared for their use as reference in water uptake characterization (see below). A single screw extruder was used (SCAMIA, Rheoscam). Prior to extrusion, water was added to adjust the starch moisture content to $30 \%(\mathrm{db})$, using a laboratory kneading machine. Extrusion was done at a screw speed of $20 \mathrm{rpm}$. The temperature profile was $\left[100{ }^{\circ} \mathrm{C} ; 110{ }^{\circ} \mathrm{C} ; 110^{\circ} \mathrm{C}\right]$ along the heating elements from the entry of the extruder to its outlet die (diameter $3 \mathrm{~mm}$ ).

\subsection{Characterizations of TPS samples}

X-Ray diffraction was used to characterize starch residual crystallinity after thermomechanical processing, and recrystallization during storage. A Bruker D8 Discover diffractometer was used: $\mathrm{Cu}$ Ka1 radiation (1.5405 $\AA$ ) was produced in a sealed tube at $40 \mathrm{kV}$ and $40 \mathrm{~mA}$, then was selected and parallelized using the two Gobël mirrors parallel optics system and collimated to produce a $500 \mu \mathrm{m}$ beam diameter. Samples were positioned perpendicular to the X-ray beam. Data were 
Version définitive du manuscrit publiée dans / Final version of the manuscript published in :

Carbohydrate Polymers (2017), Vol. 177, p. 424-432, DOI: 10.1016/j.carbpol.2017.09.012

\section{Journal homepage : http://www.elsevier.com/locate/carbpol}

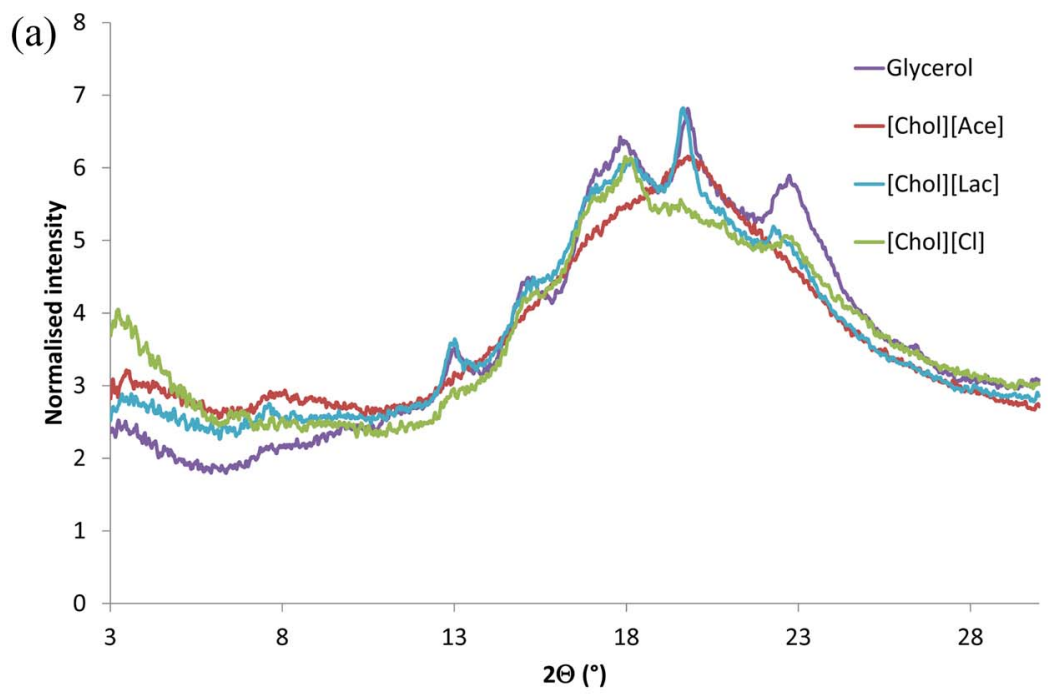

(b)

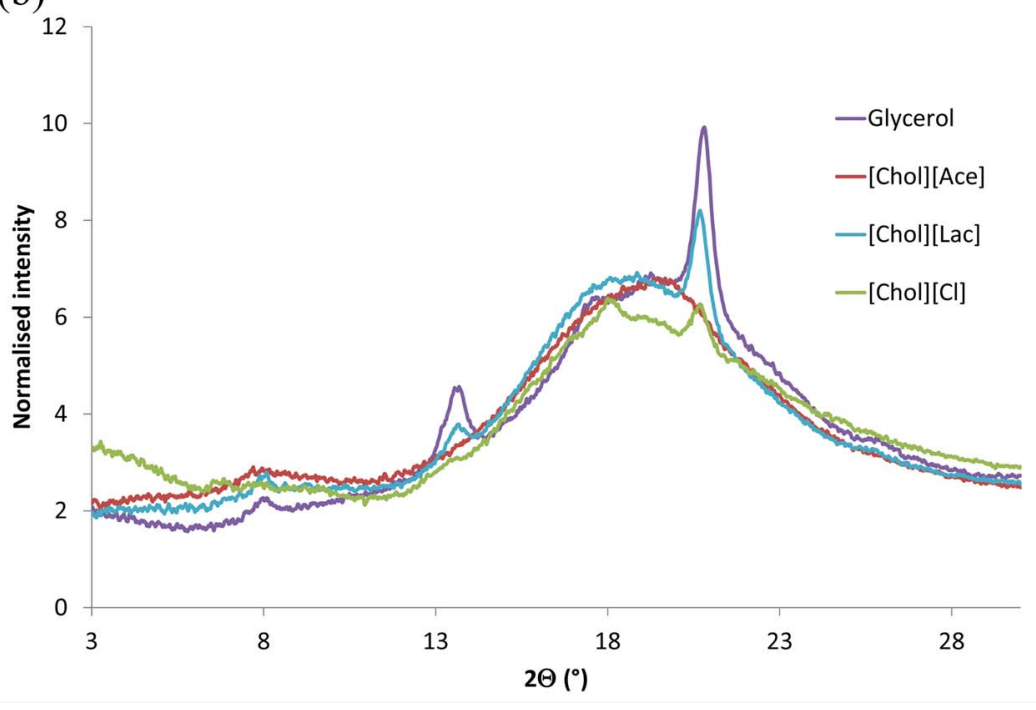

Fig. 1. Diffractograms obtained for plasticized starchs after thermocompression (a) and extrusion. collected, in the transmission mode, using a 2D detector during $10 \mathrm{~min}$ for each sample. For each TPS sample, diffractograms were first obtained just after compression molding or extrusion. Additional diffractograms were obtained on extruded samples after storage periods ranging from one week to one year.

High-Performance Size-Exclusion Chromatography coupled with Multi-Angle Laser Light Scattering and Differential Refractive Index Detection (HPSEC-MALLS-DRI) was used to determine the macromolecular characteristics. TPS were first solubilized in dimethylsulfoxide, precipitated with ethanol and dried. They were then solubilized in filtered Millipore water $(0.1 \mu \mathrm{m}$, Durapore GV membrane from Millipore) at a concentration of $0.5 \mathrm{~g} \mathrm{~L}^{-1}$ by microwave heating under pressure, as described in previous works (Rolland-Sabate, Amani, Dufour, Guilois, \& Colonna, 2003; Sciarini et al., 2015). After filtration through $5 \mu \mathrm{m}$ Durapore TM membranes (Waters, Bedford, MA, USA), $100 \mu \mathrm{L}$ of each solution was injected into the HPSEC-MALLS-DRI system. Sample recoveries were calculated from the ratio of the initial mass and the mass after filtration (Rolland-Sabate et al., 2003). The HPSEC-MALLS- DRI equipment and the method used were the same as that described previously (Sciarini et al., 2015). The SEC column was a Shodex ${ }^{\oplus} \mathrm{KW}-802.5(8 \mathrm{~mm}$ ID $\times 30 \mathrm{~cm})$ together with a KW-G guard column $(6 \mathrm{~mm}$ ID $\times 5 \mathrm{~cm})$ both from Showa Denko K.K. (Tokyo, Japan), maintained at $30^{\circ} \mathrm{C}$. The two on-line detectors were a Dawn ${ }^{\circ}$ Heleos ${ }^{\circledR}$ MALLS system fitted with a K5 flow cell and a GaAs laser, $(\lambda=658 \mathrm{~nm}$ ), supplied by Wyatt Technology Corporation (Santa
Barbara, CA, USA,) and an RID-10A refractometer from Shimadzu (Kyoto, Japan). Sample recovery rates were calculated from the ratio of the mass eluted from the column (integration of the refractometric signal) and the injected mass (Rolland-Sabate et al., 2003).

The weight-average and the number average molar masses $\left(\bar{M}_{w}, \bar{M}_{n}\right)$ and the dispersity $\left(\overline{\mathrm{M}}_{\mathrm{w}} / \overline{\mathrm{M}}_{\mathrm{n}}\right)$ were established using ASTRA ${ }^{\circ}$ software from WTC (version 6.1 for PC), as previously described (RollandSabate, Mendez-Montealvo, Colonna, \& Planchot, 2008). A value of $0.146 \mathrm{~mL} \mathrm{~g}^{-1}$ was used as the refractive index increment $(\mathrm{dn} / \mathrm{dc}$ ) for glucans and the normalization of photodiodes was achieved using a low molar mass pullulan standard (P20).

Water uptake of plasticized starches (and of the reference amorphous starch containing only water) was characterized at different water activity $\left(\mathrm{a}_{\mathrm{w}}\right)$. The sorption isotherms were determined by the static gravimetric method using over saturated salt solutions (Spiess \& Wolf, 1987; Torres \& Seijo, 2016). Ten reference salt solutions were used in the study at $25{ }^{\circ} \mathrm{C}$, to cover a range of relative humidity from $11 \%$ to $97 \%$. Samples were stored in hermetic packaging to avoid water uptake before their using for sorption measurement. They have an initial mass of $200 \mathrm{mg}$. Typically, the equilibrium was reached after 9 days, when the relative sample mass variation became lower than $1 \%$. Moisture content at equilibrium was determined by weighting before and after complete desiccation $\left(16 \mathrm{~h}\right.$ at $103{ }^{\circ} \mathrm{C}$ ) (AACC Method 4415.02, moisture/air-oven method). Each measurement was done 3 times with 5 replications. This way, the measurements uncertainties on 
Version définitive du manuscrit publiée dans / Final version of the manuscript published in :

Carbohydrate Polymers (2017), Vol. 177, p. 424-432, DOI: 10.1016/j.carbpol.2017.09.012

Journal homepage : http://www.elsevier.com/locate/carbpol

moisture content are estimated lower than $\sigma_{\mathrm{X}}=0.05 \mathrm{~kg} / \mathrm{kg}$ d.b.

Differential scanning calorimetry (DSC) was used to determine the glass transition temperature of the extruded samples with a DSC Q100 apparatus (TA Instruments, New Castle, DE, USA).Stainless steel sealed pans prevented any water loss during tests. A scan was then performed from -60 to $100{ }^{\circ} \mathrm{C}$ at $10{ }^{\circ} \mathrm{C} \cdot \mathrm{min}^{-1}$. $\mathrm{T}_{\mathrm{g}}$ was defined as the onset of the heat capacity jump on thermograms.

Dynamic Mechanical Thermal Analysis (DMTA) was used to characterize the thermo-mechanical properties of the plasticized starches. ADMA 50 apparatus (Metravib, Lyon, France) was used in tensile mode and at a frequency of $1 \mathrm{~Hz}$, for bar shape samples, with a temperature ramp from -70 to $150{ }^{\circ} \mathrm{C}$ at $3{ }^{\circ} \mathrm{C} \cdot \mathrm{min}^{-1}$ and an imposed strain of $0.05 \%$. Samples were coated with hydrophobic grease in order to limit dehydration during the test.

\section{Results and discussion}

\subsection{Influence of thermomechanical processing on starch crystallinity and} macromolecular characteristics

Both compression molding and extrusion processes allowed the thermoplasticization of starch in presence of Glycerol, [Chol][Ace], [Chol][Lac] and [Chol][Cl]. Thermomechanical processing modified both the macromolecular characteristics and the crystallinity of starch. In contrast, it was impossible to melt starch granules in presence of the precursors [Na] [Ace] and [H][Lac]. This shows the important role of the cation moiety of the salts for starch thermoplasticization.

Fig. 1 and Table 1 show the X-ray diffractograms and measured crystallinity levels, obtained for the thermoplasticized starch samples just after compression molding or extrusion. For compression molded samples, it can be observed that in presence the three choline based ionic plasticizers, the residual native A-type crystallinity (characteristic peaks at $17^{\circ}, 18.1^{\circ}$ and $23^{\circ}$ ) is smaller than in presence of glycerol. Indeed, for this widely used starch plasticizer, the simple compression molding conditions used did not allow the complete melting of starch.

This better efficiency of the ionic plasticizers is confirmed for the extruded samples: While a residual native A-type crystallinity of $3 \%$ is observed in presence of glycerol (Table 1), it is not detectable for the other samples. In addition, the SME input values measured during extrusion are lower for the ionic plasticizers than for glycerol.

Starch melt processing with glycerol is known to induce strong $\mathrm{V}_{\mathrm{H}^{-}}$ type crystallinity (peaks at $7.5^{\circ}, 13^{\circ}, 19.5^{\circ}$ and $22.5^{\circ}$, not present for native starch granules), corresponding to the complexation of amylose macromolecules with lipid impurities of corn starch and/or plasticizers (vanSoest \& Vliegenthart, 1997). The calculated levels of $\mathrm{V}_{\mathrm{H}}$-type of crystallinity (Table 1 ) show significantly lower values for the ionic plasticizers. In particular, no $\mathrm{V}_{\mathrm{H}}$-type crystallinity is detected in presence of [Chol] [Ace]. It is noteworthy that during storage for one year at $25{ }^{\circ} \mathrm{C} / 50 \% \mathrm{RH}$, all the extruded samples showed a progressive recrystallization of starch with the formation of B-type crystallinity (characteristic peaks at $5,6^{\circ}, 17^{\circ}, 19,5^{\circ}$ and $22^{\circ}$; diffractograms not shown) while the $\mathrm{V}_{\mathrm{H}}$-type crystallinity level remained constant. This phenomenon is typical of thermoplastic starch recrystallization observed in presence of glycerol (vanSoest \& Vliegenthart, 1997).

The diffractograms obtained after a storage time ranging from one week to one year showed a progressive recrystallization in B-type crystallinity. (As an example of the diffractogramms obtained for choline acetate plasticized starch are presented as supplementary data (Supplementary Figure B)) For all plasticized starches the crystallinity did not evolve significantly after 4 month. Table 1 shows the calculated B-type crystallinity levels after one year of storage. The values observed in presence of glycerol, [Chol] [Lac] and [Chol] $[\mathrm{Cl}]$ are similar, while again a different behavior is observed in presence of [Chol] [Ace], with a significantly stronger B-type recrystallization. However, the occurrence of B-type recrystallization for the three choline based ionic plasticizers is consistent with the results previously reported for starch plasticized by choline chloride based DES (Choline $\mathrm{Cl} /$ glycerol and Choline $\mathrm{Cl}$ /urea mixtures) after similar processing conditions (Leroy, Decaen et al., 2012).

The macromolecular characteristics of starch samples processed by compression molding and extrusion were studied using HPSEC-MALLSDRI. The solubilization recoveries were higher than $88 \%$ and the elution recoveries of about $99-100 \%$, which means that the following analyses are representative and enable the structural characterization of these starches.

Fig. 2 presents chromatograms for native corn starch and corn starch processed with the various plasticizers. When considering native starch (Fig. 2a), two peaks corresponding to chain concentration (obtained from the differential refractive index (DRI) signal) were observed. The first and larger one, eluting at $\sim 5.8 \mathrm{~mL}$, corresponds to amylopectin population, while the second, and smaller, eluting at $\sim 6.5 \mathrm{~mL}$, corresponds to amylose.

The chromatograms and the molar mass distributions of corn starches obtained after compression molding exhibit similar patterns as native starch, with a slight shift of the amylopectin peak to lower elution volumes, i.e. to higher molecular size, after compression molding.

Table 1

Influence of thermomechanical processing on thermoplastic starch crystallinity and influence of aging of extruded samples on starch recrystallization.

Plasticizers

Crystallinity after processing

\begin{tabular}{|c|c|c|c|c|}
\hline & \multirow{2}{*}{$\begin{array}{l}\text { Compression molding } \\
\left(120^{\circ} \mathrm{C}, 5 \mathrm{~min}\right) \\
\text { Residual native crystallinity } \\
\text { (A-type) }\end{array}$} & \multicolumn{3}{|c|}{$\begin{array}{l}\text { Extrusion (microcompounder) } \\
\quad\left(120^{\circ} \mathrm{C}, 100 \mathrm{rpm}, 5 \mathrm{~min}\right)\end{array}$} \\
\hline & & $\begin{array}{l}\text { Residual native crystallinity } \\
\text { (A-type) }\end{array}$ & $\begin{array}{l}\text { Induced cristallinity } \\
\left(\mathrm{V}_{\mathrm{H}} \text {-type }\right)\end{array}$ & $\begin{array}{l}\mathrm{SME} \\
\left(\mathrm{J} \mathrm{g}^{-1}\right)\end{array}$ \\
\hline Glycerol & strong & Traces $(3 \%)$ & Strong $(16 \%)$ & 443 \\
\hline [Chol] [Ace] & traces & None $(0 \%)$ & None $(0 \%)$ & 362 \\
\hline [Chol] [Lac] & low & None $(0 \%)$ & Medium (12\%) & 402 \\
\hline$[\mathrm{Chol}][\mathrm{Cl}]$ & low & None $(0 \%)$ & Low (7\%) & 322 \\
\hline
\end{tabular}

Plasticizers

Crystallinity levels after 1 year at $25^{\circ} \mathrm{C} / 57 \% \mathrm{RH}$

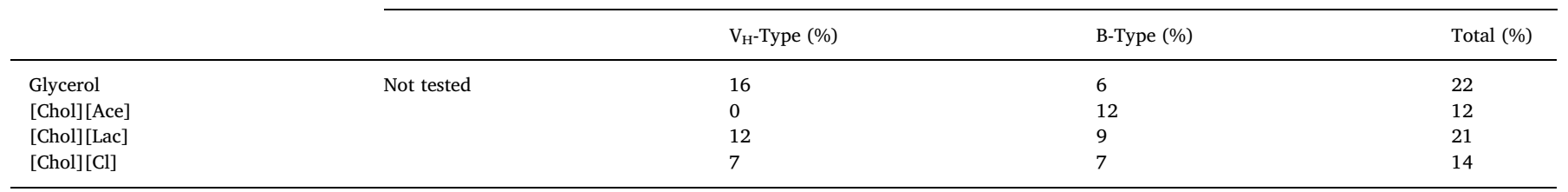




\section{Journal homepage : http://www.elsevier.com/locate/carbpol}
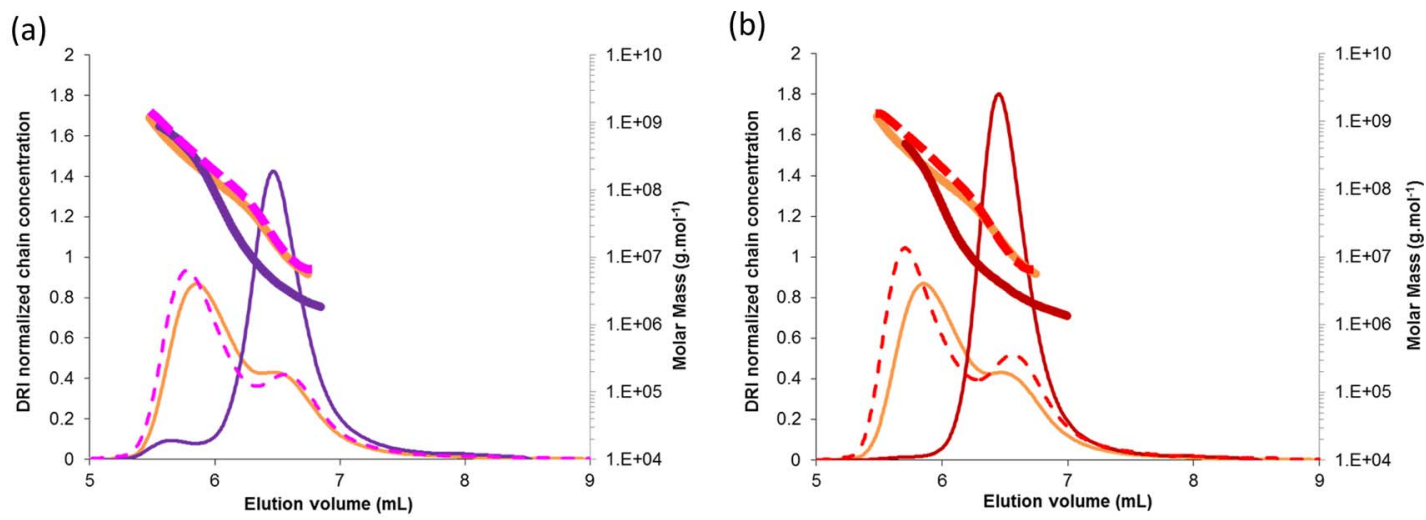

(c)

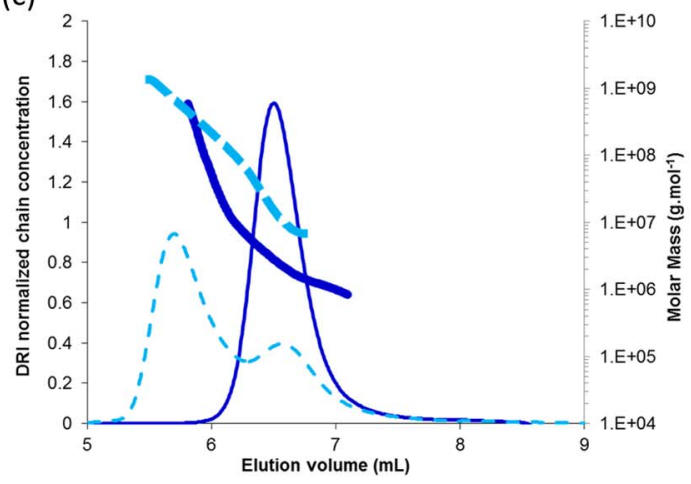

(d)

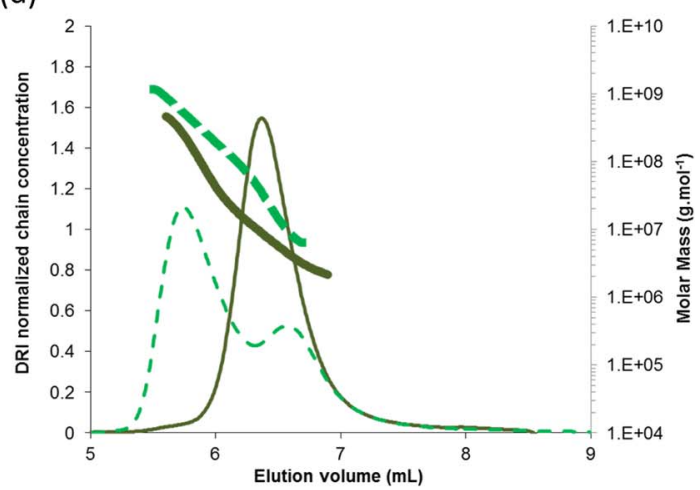

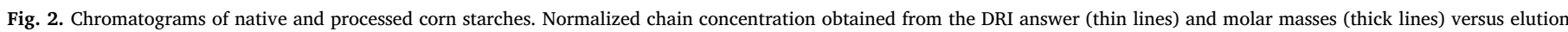

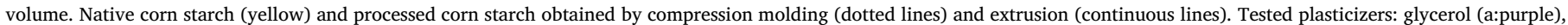

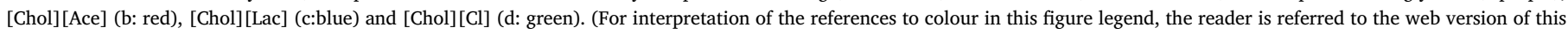
article.)

Moreover one can note the higher values of average molar masses $\left(\bar{M}_{w}\right)$ obtained for corn starches after compression molding with all the plasticizers compared to native corn starch (Table 2). An increase of $\overline{\mathrm{M}}_{\mathrm{w}}$ is not possible in these conditions, in addition $\overline{\mathrm{M}}_{\mathrm{n}}$ decreases. The calculated $\overline{\mathrm{M}}_{\mathrm{w}}$ is more affected than $\overline{\mathrm{M}}_{\mathrm{n}}$ by the presence of large molar mass fractions. This increase of apparent $\bar{M}_{w}$ values could then be explained by the formation of few aggregates during the compression molding process that were not solubilized properly and eluted at the early beginning of the chromatogram, producing a bias in the calculation of $\overline{\mathrm{M}}_{\mathrm{w}}$. Such a phenomenon had already been observed for starches treated with mild processes (results not shown). Then $\overline{\mathrm{M}}_{\mathrm{w}}$ values cannot be considered as quantitative. Nevertheless, it is possible to use them in a qualitative approach to compare the effects of various plasticizers. $\overline{\mathrm{M}}_{\mathrm{n}}$ of corn starches after compression molding $\left(6.4 \times 10^{7} \mathrm{~g}\right.$ $\mathrm{mol}^{-1}-7.7 \times 10^{7} \mathrm{~g} \mathrm{~mol}^{-1}$ ) are slightly lower than native corn starch (9.3. $\times 10^{7}$ g.mol ${ }^{-1}$, Table 2). This accounts for a slight degradation of the macromolecules during the process which seems to be slightly more pronounced where a choline-based plasticizer is used as the $\overline{\mathrm{M}}_{n}$ of corn starches after compression molding with choline salts $\left(6.4 \times 10^{7} \mathrm{~g} \mathrm{~mol}^{-1}\right.$ to $\left.6.9 \times 10^{7} \mathrm{~g} \mathrm{~mol}^{-1}\right)$ are slightly lower than with glycerol $\left(7.7 \times 10^{7} \mathrm{~g} \mathrm{~mol}^{-1}\right)$. The higher proportion of aggregates (higher shift of the main peak to lower elution volumes and higher $\overline{\mathrm{M}}_{\mathrm{w}}$ of the main population) in these starches processed with choline salts and the slightly higher proportion of smaller molecules (broadening of the second peak towards lower sizes) explains their higher $\overline{\mathrm{M}}_{\mathrm{w}}$ and dispersity.

By considering now the extrusion process, the chromatogram of extruded corn starches exhibited mainly one peak eluting at $6.3-6.5 \mathrm{~mL}$ and a clearly lower molar mass for this main population than native starches and starches obtained by compression molding (Fig. 2). This shift of the main population to higher elution volumes (i.e. to smaller molecular size), is due to a drastic amylopectin degradation and

Table 2

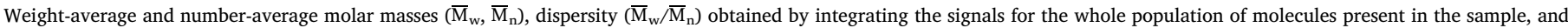
molar mass of the main fraction determined by HPSEC-MALLS, for corn starch samples processed with different plasticizers and native corn starch.

\begin{tabular}{|c|c|c|c|c|c|c|c|c|}
\hline \multirow[t]{2}{*}{ Plasticizers } & \multicolumn{4}{|c|}{ Compression molding $\left(120^{\circ} \mathrm{C}, 5 \mathrm{~min}\right)$} & \multicolumn{4}{|c|}{ Extrusion (microcompounder) $\left(120^{\circ} \mathrm{C}, 100 \mathrm{rpm}, 5 \mathrm{~min}\right)$} \\
\hline & $\overline{\mathrm{M}}_{\mathrm{W}}\left(10^{6} \mathrm{~g} \mathrm{~mol}^{-1}\right)$ & $\overline{\mathrm{M}}_{\mathrm{n}}\left(10^{6} \mathrm{~g} \mathrm{~mol}^{-1}\right)$ & $\overline{\mathrm{M}}_{\mathrm{w}} / \overline{\mathrm{M}}_{\mathrm{n}}$ & $\begin{array}{l}\text { Main peak }{ }^{\mathrm{a}}\left(10^{6} \mathrm{~g} \mathrm{~mol}^{-1}\right) \\
\text { at the apex }\end{array}$ & $\overline{\mathrm{M}}_{\mathrm{w}}\left(10^{6} \mathrm{~g} \mathrm{~mol}^{-1}\right)$ & $\overline{\mathrm{M}} \mathrm{n}\left(10^{6} \mathrm{~g} \mathrm{~mol}^{-1}\right)$ & $\overline{\mathrm{M}}_{\mathrm{w}} / \overline{\mathrm{M}}_{\mathrm{n}}$ & $\begin{array}{l}\text { Main peak }{ }^{\mathrm{a}}\left(10^{6} \mathrm{~g} \mathrm{~mol}^{-1}\right) \\
\text { at the apex }\end{array}$ \\
\hline Glycerol & 319.0 & 77.0 & 4.2 & 435.0 & 38.0 & 5.5 & 7.0 & 4.6 \\
\hline [Chol] [Ace] & 414.0 & 64.0 & 6.5 & 671.0 & 5.5 & 3.5 & 1.6 & 4.3 \\
\hline [Chol] [Lac] & 441.0 & 66.0 & 5.9 & 687.0 & 3.4 & 2.4 & 1.4 & 2.8 \\
\hline$[\mathrm{Chol}][\mathrm{Cl}]$ & 357.0 & 69.0 & 5.2 & 530.0 & 11.0 & 6.6 & 1.7 & 8.8 \\
\hline $\begin{array}{l}\text { Native corn } \\
\text { starch }^{\mathrm{b}}\end{array}$ & 198.0 & 93.0 & 2.1 & 237.0 & & & & \\
\hline
\end{tabular}

\footnotetext{
${ }^{\text {a }}$ The molar mass of the main fraction was determined by taking the average values on 5 slices at the apex of the main DRI peak.

b without process.
} 
Carbohydrate Polymers (2017), Vol. 177, p. 424-432, DOI: 10.1016/j.carbpol.2017.09.012

Journal homepage : http://www.elsevier.com/locate/carbpol

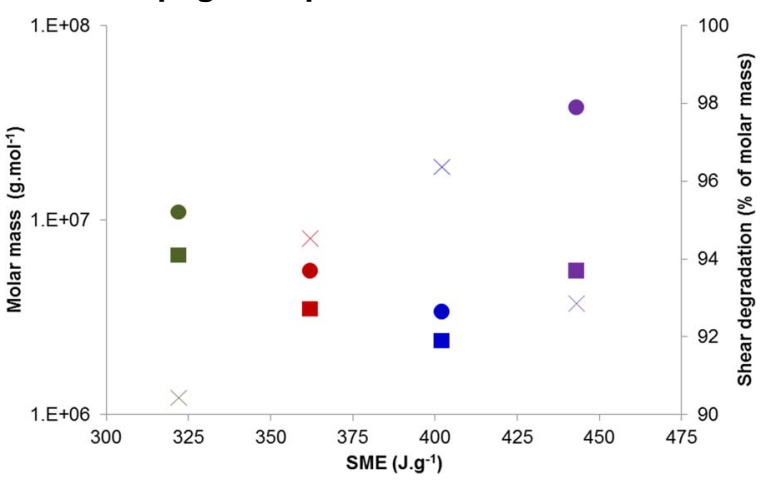

Fig. 3. Molar masses versus specific mechanical energy (SME) for corn starch extruded with glycerol (purple), [Chol][Ace] (dark red), [Chol] [Lac] (dark blue) and [Chol][Cl] (dark green). $\overline{\mathrm{M}}_{\mathrm{w}}$ (Circles), $\overline{\mathrm{M}}_{\mathrm{n}}$ (squares), \% of molar mass decrease (crosses). (For interpretation of the references to colour in this figure legend, the reader is referred to the web version of this article.)

explained by a co-elution of the degradation products of amylopectin and amylose, as was already observed for extruded starches (Myllymaki et al., 1997; Sankri et al., 2010; van den Einde, Akkermans, van der Goot, \& Boom, 2004; van den Einde, Bolsius et al., 2004), and also for starches processed with ILs (Sciarini et al., 2015). Moreover, $\overline{\mathrm{M}}_{\mathrm{n}}$ of extruded corn starches $\left(2.4 \times 10^{6} \mathrm{~g} \mathrm{~mol}^{-1}-6.6 \times 10^{6} \mathrm{~g} \mathrm{~mol}^{-1}\right)$ are about one decade lower than the one of corn starches after compression molding $\left(6.4 \times 10^{7} \mathrm{~g} \mathrm{~mol}^{-1}-7.7 \times 10^{7} \mathrm{~g} \mathrm{~mol}^{-1}\right.$, Table 2). This indicates a lower impact of compression molding on the degradation of amylopectin. Finally, no evidence of amylose degradation is found as the second peak is not shifted to higher elution volumes (i.e. to lower molecular size). This higher degradation of amylopectin molecule during extrusion is explained by a chain scission mechanism caused by shearing. Considering now the plasticizer effect on extruded starches, the amylopectin peak vanishes when choline based plasticizers are used but a small fraction of residual amylopectin is detected in starch extruded with glycerol (Fig. 2a). This means that choline salts induce a higher degradation of amylopectin than glycerol during extrusion processing. The dispersity is also clearly lower for corn starches extruded with choline based plasticizers $(\sim 1.4-1.7$, Table 2$)$ because of the reduction of the overall peak broadness.

The chain scission of starch polysaccharides is known to increase with the SME applied during extrusion. The plot of molar masses versus SME for the corn starch extruded with the four plasticizers (Fig. 3) shows a clear decrease of molar masses with SME for corn starch extruded with choline based plasticizers. Moreover, the calculation of the $\%$ of molar mass decrease due to shearing $\left(=100 \times\left(\overline{\mathrm{M}}_{\text {ncompressionmolding }}-\overline{\mathrm{M}}_{\text {nextrusion }}\right)\right.$ / $\overline{\mathrm{M}}_{\text {ncompressionmolding }}$ ) shows that the chain scission due to shearing is lower with [Chol][Cl] than with [Chol][Ace] and [Chol][Lac], but also in line with a lower SME applied with [Chol][Cl]. The molar masses of starch extruded with glycerol do not fall in the quasi linear relation linking the molar mass and the SME of starches extruded with choline salts. In particular starch extruded with glycerol is less degraded and exhibits a lower loss of molar mass despite a higher SME applied. This means that the mechanism of chain scission differs. The higher hydrolysis of starch macromolecules produced by the ionic plasticizers combined with temperature probably helps the chain scission during extrusion.

These results may explain the higher efficiency of ionic plasticizers (compared to glycerol) for starch destructuration/thermoplasticization which leads to the complete disappearance of the native A-type crystallinity (Fig. 1b, Table 1) after extrusion. However, in contradiction to the work of Sciarini et al. (Sciarini et al., 2015) on starches in ILs solutions, it seems that during extrusion, the presence of chloride anions do not produce a higher chain scission in starches than with acetate anions. Actually the lower molar masses are here observed for the two bio-ILs: [Chol][Ace] and [Chol][Lac] (Table 2). So unexpectedly, the use of $[\mathrm{Chol}][\mathrm{Cl}]$ allows a better compromise between an efficient destructuration at low SME and limited chain scission of starch during extrusion. Note that another choline (citrate) salt has recently been reported to strongly degrade starch during processing (Zdanowicz \& Johansson, 2016).

\subsection{Water uptake and thermo-mechanical properties of thermoplastic starches}

Sorption isotherms at $25{ }^{\circ} \mathrm{C}$ are plotted in Fig. 4 for the glycerol and salt plasticized starches with $23 \%$ d.b. of plasticizer and compared to the one of the amorphous starch reference containing only water. To complete this experimental study, sorption isotherms were modeled by the Guggenheim-Anderson-Boer (GAB) model (Blahovec \& Yanniotis, 2009; Timmermann, Chirife, \& Iglesias, 2001):

$\frac{X}{X_{m}}=\frac{C_{G} K a_{w}}{\left(1-K a_{w}\right)\left(1+\left(C_{G}-1\right) K a_{w}\right)}$

where $\mathrm{X}$ is the moisture content of the material on dry basis $\left(\mathrm{kg} \cdot \mathrm{kg}^{-1}\right.$ d.b.).

The constant parameters of the model $\left(\mathrm{C}_{\mathrm{G}}, \mathrm{K}\right.$ and $\left.\mathrm{X}_{\mathrm{m}}\right)$ were estimated by fitting the model calculated values to experimental ones by minimizing the root mean square (RMSE) between measured and predicted values (MATLAB ${ }^{\mathrm{rm}}$ was used for parameter estimation).

$R M S E=\sqrt{\frac{\sum_{i=1}^{N}\left(X_{\text {exp }, i}-X_{i}\right)^{2}}{N}}$

where $\mathrm{X}_{\exp }$ and $\mathrm{X}$ are respectively the experimental and predicted moisture content values $\left(\mathrm{kg} \mathrm{kg}^{-1}\right.$ d.b.) and $\mathrm{N}$ is the number of moisture content measurements. The obtained GAB parameters and RMSE values for all thermoplastic starches are given in supplementary data (Supplementary Table A). RMSE was always lower than $3 \times 10^{-2}$ qualifying the fitting model.

According to the works of Godbillot et al. (Godbillot, Dole, Joly, Roge, \& Mathlouthi, 2006) on glycerol plasticized starch, and Bendaoud and Chalamet (Bendaoud \& Chalamet, 2013) on imidazolium ionic liquids, the influence of all plasticizers on water uptake strongly depends on the water activity range. Fig. 4 shows that for low water activity (typically below $\mathrm{a}_{\mathrm{w}}=0.3$ ) plasticized starches are less hygroscopic than native starch. Concurrently, for high water activity (especially above $a_{w}=0.6$ ), the water uptake of plasticized starches is always much higher than for amorphous starch. This behavior reflects the "competition" between water molecules, plasticizers and starch's hydroxyl groups, which can interact with each other (Godbillot et al., 2006). According to the above cited works, the maximum amount of glycerol or imidazolium ionic liquid that can act as a plasticizer is in the range 20-22\% (Bendaoud \& Chalamet, 2013; Godbillot et al., 2006). Consequently, for the present plasticizer dry basis content (23\%), a phase separation can occur and the water uptake at high water activity is expected to reflect the hygroscopic behavior of "free plasticizer". A similar behavior was described in the case of glycerol plasticized high amylose maize starch: for several glycerol contents, the increasing water sorption involved in the hydrophilic character of glycerol was evidenced (Bertuzzi, Armada, \& Gottifredi, 2007).

Fig. 4 shows that the water uptake levels in the $0.6<\mathrm{a}_{\mathrm{w}}$ range, are higher for the ionic plasticizers than for glycerol. For $\mathrm{a}_{\mathrm{w}}=1$, equilibrium moisture content tends to 0.24 for starch, 0.67 for starch/glycerol and is higher for ionic plasticizers $(>0.7)$. The highest water uptake is observed for [Chol] [Cl]. In order to verify if this is due to their respective hygroscopicity, it would be interesting to investigate the water sorption isotherms of these different plasticizers in future work.

Now, if we focus on the medium range of water activity $\left(0.3<\mathrm{a}_{\mathrm{w}}<0.6\right)$, the water uptake values are relatively close for all plasticizers. We can note that in the range of $\left(0.2<\mathrm{a}_{\mathrm{w}}<0.4\right)$, the water uptake varies slightly (variation lower than $0.05 \mathrm{~kg} \mathrm{~kg}^{-1}$ d.b. for all thermoplastic starch). In this range, an inflexion point is visible (for 
Version définitive du manuscrit publiée dans / Final version of the manuscript published in :

Carbohydrate Polymers (2017), Vol. 177, p. 424-432, DOI: 10.1016/j.carbpol.2017.09.012

Journal homepage : http://www.elsevier.com/locate/carbpol

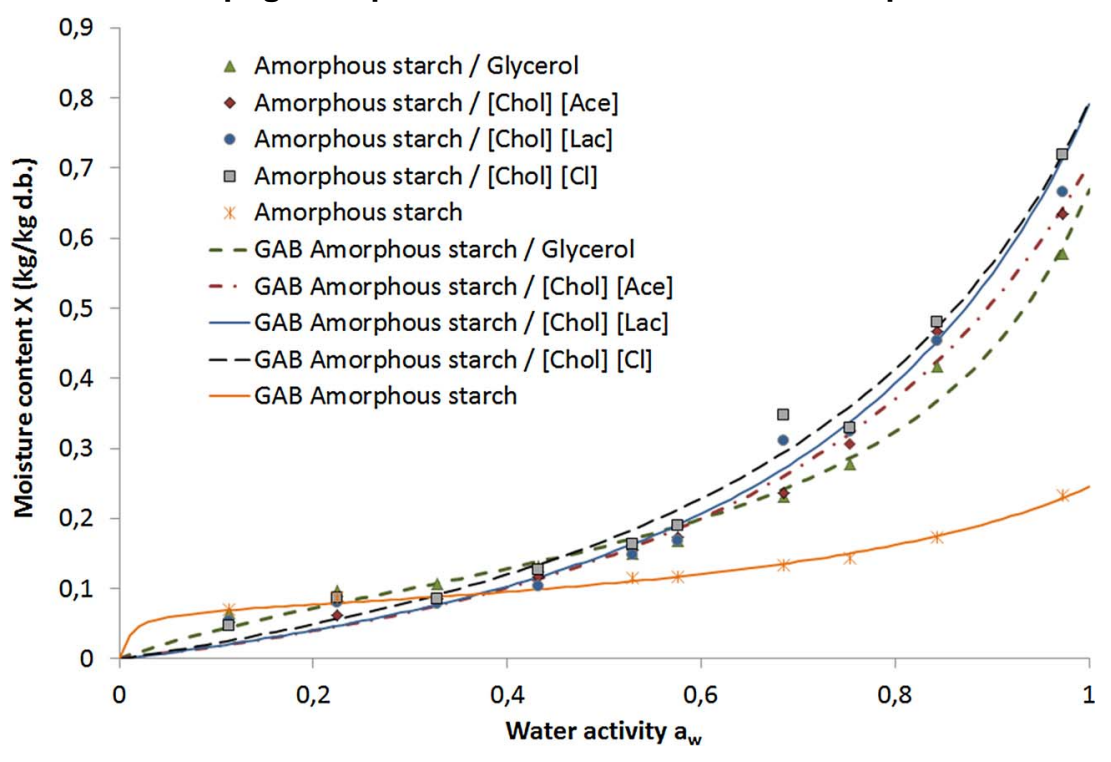

Fig. 4. Sorption isotherms of thermoplastic starches and amorphous starch at $25^{\circ} \mathrm{C}$.

$\mathrm{a}_{\mathrm{w}} \sim 0.22 \mathrm{~kg} \mathrm{~kg}^{-1}$ d.b.) in the isotherm curve of amorphous starch. It is less clear for glycerol and salt plasticized starches due to difficulties in describing their behavior at low moisture contents with GAB model with the limited number of experimental data available.

It was suggested that such an inflexion point may be used to detect the glass transition of hygroscopic amorphous biopolymers (Carter \& Schmidt, 2012). The inflexion point corresponds to a critical $\mathrm{a}_{\mathrm{w}}$ for which the glass transition temperature of the biopolymer is supposed to be equal to the temperature at which the sorption experiments are conducted (Carter \& Schmidt, 2012). However, the authors suggest the use of Dynamic Vapor Sorption (DVS) for a precise determination of this transition (Carter \& Schmidt, 2012). Therefore in future work, it would be interesting to characterize our samples by DVS to further investigate this possibility of observing this key transition of thermoplastic starch as a function of water activity.

For the moment, we have evaluated the $\mathrm{T}_{\mathrm{g}}$ of our plasticized starches conditioned at a relative humidity of $57 \%$ by a thermal method. $\mathrm{T}_{\mathrm{g}}$ values were determined from DSC thermograms available as supplementary data (supplementary figure A). They are reported in Table 3, together with the samples' water contents and thermomechanical properties. For all plasticized starches, values are between -5 and $7{ }^{\circ} \mathrm{C}$. Nevertheless, starch's $\mathrm{T}_{\mathrm{g}}$ depression is a combination of plasticizer and water effect. Therefore, it is striking that for the ionic plasticizers water content and/or $\mathrm{T}_{g}$ values are higher than for glycerol. This indicates that they are worse $\mathrm{T}_{\mathrm{g}}$ depressors than glycerol (since water molecules have a strong plasticizing effect on starch). For the two ionic liquids [Chol][Ace] and [Chol] [Lac] this result is in line with a previous screening study on starch films obtained by casting from solutions in water (Colomines et al., 2016). Besides, the fact that [Chol] [Cl] leads to similar $\mathrm{T}_{\mathrm{g}}$ depression shows that this biocompatible organic salt, despite not being an ionic liquid, can be used directly to plasticize starch in the presence of water.

However, the thermomechanical characterization results show that

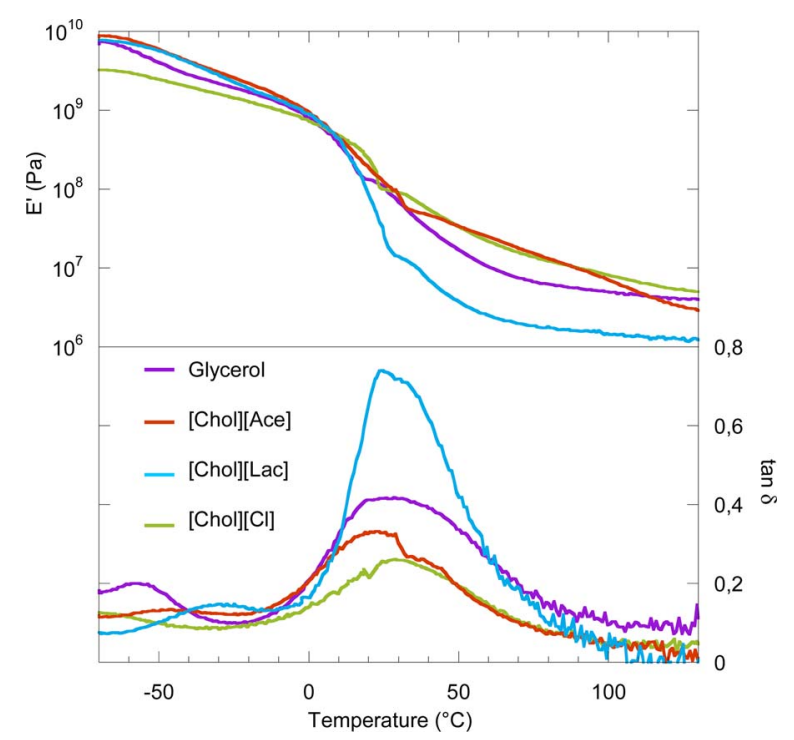

Fig. 5. Storage modulus and $\tan \delta$ measured by dynamic thermomechanical analysis of plasticized starch.

the nature of the cation has an influence on plasticized starches' behavior. Fig. 5 displays the variation of the storage modulus E' and $\tan \delta$ vs. temperature for starch containing the different plasticizers. For all materials, the $\tan \delta$ presents two relaxations:

A small relaxation is observed at low temperature $\left(\mathrm{T}_{\alpha 2}\right.$ values below $-20{ }^{\circ} \mathrm{C}$ ) that typically reflects the presence of a plasticizer rich phase due to phase a separation, as previously reported for starch plasticized by more than $20 \%$ of glycerol (Godbillot et al., 2006) or imidazolium ionic liquid (Bendaoud \& Chalamet, 2013). In the case of [Chol] [Cl], the maximum of the $\tan \delta$ peak associated to this low temperature

Table 3

Thermomechanical properties of extruded starch samples.

\begin{tabular}{|c|c|c|c|c|c|c|}
\hline \multirow[b]{2}{*}{ Plasticizer } & \multirow{2}{*}{$\begin{array}{l}\text { Water content }(\%) \\
\% \text { water }(57 \% \mathrm{RH})\end{array}$} & \multicolumn{4}{|l|}{ DMTA } & \multirow{2}{*}{$\begin{array}{l}\text { DSC } \\
\mathrm{T}_{\mathrm{g}}\left({ }^{\circ} \mathrm{C}\right)\end{array}$} \\
\hline & & $\mathrm{E}_{\text {glassy }}\left(10^{9} \mathrm{~Pa}\right)$ determined at $-60^{\circ} \mathrm{C}$ & $\mathrm{E}_{\text {rubbery }}\left(10^{6} \mathrm{~Pa}\right)$ determined at $120^{\circ} \mathrm{C}$ & $\mathrm{T}_{\alpha 1}\left({ }^{\circ} \mathrm{C}\right)\left(3^{\circ} \mathrm{C} \cdot \mathrm{min}^{-1}\right)$ & $\mathrm{T}_{\alpha 2}\left({ }^{\circ} \mathrm{C}\right)\left(3^{\circ} \mathrm{C} \cdot \mathrm{min}^{-1}\right)$ & \\
\hline Glycerol & 13 & 7.3 & 6.7 & 28 & -56 & -5 \\
\hline [Chol] [Ace] & 16 & 8.7 & 8.3 & 22 & -47 & 7 \\
\hline$[\mathrm{Chol}][\mathrm{Cl}]$ & 15 & 3.3 & 9.2 & 30 & $<-70$ & 2 \\
\hline [Chol][Lac] & 13 & 7.7 & 1.6 & 28 & -28 & 0 \\
\hline
\end{tabular}


relaxation is not clearly observed and may be at a temperature below $-70^{\circ} \mathrm{C}$.

A main relaxation associated to the calorimetric glass transition of the starch rich phase is also observed, with a maximum situated at $\mathrm{T}_{\alpha 1}$ ranging between 22 and $30{ }^{\circ} \mathrm{C}$. These $\mathrm{T}_{\alpha 1}$ values taken at the maximum of the peak of $\tan \delta$ are higher than the calorimetric (DSC) $\mathrm{T}_{\mathrm{g}}$ values discussed above. Such a difference between the two techniques is typical for TPS and has been discussed in detail (Kalichevsky, Jaroszkiewicz, Ablett, Blanshard, \& Lillford, 1992). In our case, the difference is quite strong $\left(25-30{ }^{\circ} \mathrm{C}\right)$ due to the fact that $\mathrm{T}_{\mathrm{g}}$ was defined as the onset of the heat capacity jump on DSC thermograms. Closer values of $\mathrm{T}_{\alpha 1}$ would have been obtained by considering the onset of the change of slope in DTMA storage modulus curves. However, as can be seen on Fig. 5, our DMTA curves do not allow for a precise determination of this change of slope. Also the unavoidable dehydration during DMTA measurements induces an increase of $\mathrm{T}_{\alpha}$ during the heating ramp.

Large differences are observed in the tan $\delta$ peak amplitude, in relation to the difference between the glassy and the rubbery modulus values (Table 3) The E' modulus in the rubbery state of starch plasticized by [Chol][Lac] is lower than for all other plasticizers, including glycerol. Concurrently, [Chol][Ace] and [Chol][Cl] lead to similar performances in the rubbery state.

\section{Conclusions}

In the context of the recent interest for the plasticization of starch by liquid salts based plasticizers such as ionic liquids and deep eutectic solvents, glycerol, a typical starch plasticizer, was compared with three choline salts: Raw choline chloride (which is a solid in dry state), and two ionic liquids synthesized from this precursor (choline acetate and choline lactate).

These ionic plasticizers were shown to allow a more efficient melting of native starch in both simple compression molding and extrusion processes. The investigation of macromolecular structure changes during processing shows that this efficiency can be ascribed to a starch chain scission mechanism resulting in lower specific mechanical energy input need for thermoplasticization compared to glycerol. However, the plasticizing effect in the materials obtained is less important than for glycerol, according to the glass transition temperatures and water contents. The nature of the anion moiety of the choline salt strongly affects both the chain scission intensity and the thermomechanical properties. Compared to the ionic liquids synthesized (Choline Acetate and Choline Lactate), cheap and raw commercial Choline chloride leads to a good compromise between limited chain scission, and final properties.

Beside thermoplastic starch materials potential applications, this efficiency of choline chloride for starch destructuration opens perspectives for food matrix design. Effectively, this salt also known as vitamin B4 is currently investigated as functional additive for dietary products (Asomaning et al., 2017).

\section{Acknowledgements}

We are grateful for the financial support provided by the LIMPONAN project funded by the "Région de Pays de la Loire" Council. We thank B. Pontoire for his experimental contributions.

\section{Appendix A. Supplementary data}

Supplementary data associated with this article can be found, in the online version, at doi:10.1016/j.carbpol.2017.09.012.

\section{References}

$001142 \mathrm{~A} 1$

Abbott, A. P., Abolibda, T. Z., Davis, S. J., Emmerling, F., Lourdin, D., Leroy, E., et al. (2014). Glycol based plasticisers for salt modified starch. Rsc Advances, 4(76), 40421-40427.

Abbott, A. P. (2009). Results presented at the Royal Society summer science exhibition (http:// www.leicester-ils.co.uk/materials.html).

Abbott, A. P., Ballantyne, A. D., Conde, J. P., Ryder, K. S., \& Wise, W. R. (2012). Salt modified starch: Sustainable, recyclable plastics. Green Chemistry, 14(5), 1302-1307.

Abbott, A. P., Conde, J. P., Davis, S. J., \& Wise, W. R. (2012). Starch as a replacement for ureaformaldehyde in medium density fibreboard. Green Chemistry, 14(11), 3067-3070.

Asomaning, J., Zhao, Y. Y., Lewis, E. D., Wu, J. P., Jacobs, R. L., Field, C. J., et al. (2017). The development of a choline rich cereal based functional food: Effect of processing and storage. Lwt-Food Science and Technology, 75, 447-452.

Barron, C., Bouchet, B., Della Valle, G., Gallant, D. J., \& Planchot, V. (2001). Microscopical study of the destructuring of waxy maize and smooth pea starches by shear and heat at low hydration. Journal of Cereal Science, 33(3), 289-300.

Barron, C., Della Valle, G., Colonna, P., \& Vergnes, B. (2002). Energy balance of low hydrated starches transition under shear. Journal of Food Science, 67(4), 1426-1437.

Bendaoud, A., \& Chalamet, Y. (2013). Effects of relative humidity and ionic liquids on the water content and glass transition of plasticized starch. Carbohydrate Polymers, 97(2), 665-675.

Bertuzzi, M. A., Armada, M., \& Gottifredi, J. C. (2007). Physicochemical characterization of starch based films. Journal of Food Engineering, 82(1), 17-25.

Blahovec, J., \& Yanniotis, S. (2009). Modified classification of sorption isotherms. Journal of Food Engineering, 91(1), 72-77.

Buleon, A., Colonna, P., Planchot, V., \& Ball, S. (1998). Starch granules: Structure and biosynthesis. International Journal of Biological Macromolecules, 23(2), 85-112.

Carter, B. P., \& Schmidt, S. J. (2012). Developments in glass transition determination in foods using moisture sorption isotherms. Food Chemistry, 132(4), 1693-1698.

Colomines, G., Decaen, P., Lourdin, D., \& Leroy, E. (2016). Biofriendly ionic liquids for starch plasticization: A screening approach. Rsc Advances, 6(93), 90331-90337.

Fleche, G., Gosset, S., \& Lambla, M. (1996). Thermoformable compositions, process for preparing them and their use for obtaining thermoformed articles.

Fukaya, Y., Iizuka, Y., Sekikawa, K., \& Ohno, H. (2007). Bio ionic liquids: Room temperature ionic liquids composed wholly of biomaterials. Green Chemistry, 9(11), 1155-1157.

Godbillot, L., Dole, P., Joly, C., Roge, B., \& Mathlouthi, M. (2006). Analysis of water binding in starch plasticized films. Food Chemistry, 96(3), 380-386.

Halley, P. J., Truss, R. W., Markotsis, M. G., Chaleat, C., Russo, M., Sargent, A. L., et al. (2008). A review of biodegradable thermoplastic starch polymers. In M. C. Celina, \& R. A. Assink (Eds.). Polymer durability and radiation effects (pp. 287-300). Washington: Amer Chemical Soc.

Kalichevsky, M. T., Jaroszkiewicz, E. M., Ablett, S., Blanshard, J. M. V., \& Lillford, P. J. (1992) The glass-transition of amylopectin measured by DSC, DMTA and NMR. Carbohydrate Polymers, 18(2), 77-88.

Leroy, E., Decaen, P., Jacquet, P., Coativy, G., Pontoire, B., Reguerre, A. L., et al. (2012). Deep eutectic solvents as functional additives for starch based plastics. Green Chemistry, 14(11), 3063-3066.

Leroy, E., Jacquet, P., Coativy, G., Reguerre, A. L., \& Lourdin, D. (2012). Compatibilization of starch-zein melt processed blends by an ionic liquid used as plasticizer. Carbohydrate Polymers, 89(3), 955-963.

Liu, D., Qi, Z. G., Zhang, Y., Xu, J., \& Guo, B. H. (2015). Poly(butylene succinate) (PBS)/ionic liquid plasticized starch blends: Preparation, characterization, and properties. StarchStarke, 67(9-10), 802-809.

Lourdin, D., Coignard, L., Bizot, H., \& Colonna, P. (1997). Influence of equilibrium relative humidity and plasticizer concentration on the water content and glass transition of starch materials. Polymer, 38(21), 5401-5406.

Myllymaki, O., Eerikainen, T., Suortti, T., Forssell, P., Linko, P., \& Poutanen, K. (1997). Depolymerization of barley starch during extrusion in water glycerol mixtures. Food Science and Technology-Lebensmittel-Wissenschaft \& Technologie, 30(4), 351-358.

Petkovic, M., Ferguson, J. L., Gunaratne, H. Q. N., Ferreira, R., Leitao, M. C., Seddon, K. R., et al. (2010). Novel biocompatible cholinium-based ionic liquids-toxicity and biodegradability. Green Chemistry, 12(4), 643-649.

Radosevic, K., Bubalo, M. C., Srcek, V. G., Grgas, D., Dragicevic, T. L., \& Redovnikovic, I. R. (2015). Evaluation of toxicity and biodegradability of choline chloride based deep eutectic solvents. Ecotoxicology and Environmental Safety, 112, 46-53.

Ramesh, S., Shanti, R., \& Morris, E. (2012). Studies on the plasticization efficiency of deep eutectic solvent in suppressing the crystallinity of corn starch based polymer electrolytes. Carbohydrate Polymers, 87(1), 701-706.

Rolland-Sabate, A., Amani, N. G., Dufour, D., Guilois, S., \& Colonna, P. (2003). Macromolecular characteristics of ten yam (Dioscorea spp.) starches. Journal of the Science of Food and Agriculture, 83(9), 927-936.

Rolland-Sabate, A., Mendez-Montealvo, M. G., Colonna, P., \& Planchot, V. (2008). Online determination of structural properties and observation of deviations from power law behavior. Biomacromolecules, 9(7), 1719-1730.

Salmon, N. (1993). Study of thermoplastic starch-based materials. University of Strasbourg I Vol. PhD dissertation, p. 253

Sankri, A., Arhaliass, A., Dez, I., Gaumont, A. C., Grohens, Y., Lourdin, D., et al. (2010). Thermoplastic starch plasticized by an ionic liquid. Carbohydrate Polymers, 82(2), 256-263.

Sciarini, L. S., Rolland-Sabate, A., Guilois, S., Decaen, P., Leroy, E., \& Le Bail, P. (2015). Understanding the destructuration of starch in water-ionic liquid mixtures. Green Chemistry, 17(1), 291-299.

Spiess, W., \& Wolf, W. (1987). Critical evaluation of methods to determine moisture sorption isotherms. In B. Louis (Ed.). Water activity: theory and applications to food (pp. 215-233). New York: CRC Press.

Timmermann, E. O., Chirife, J., \& Iglesias, H. A. (2001). Water sorption isotherms of foods and foodstuffs: BET or GAB parameters? Journal of Food Engineering, 48(1), 19-31.

Torres, M. D., \& Seijo, J. (2016). Water sorption behaviour of by-products from the rice industry. Industrial Crops and Products, 86, 273-278.

van den Einde, R. M., Akkermans, C., van der Goot, A. J., \& Boom, R. M. (2004). Molecular breakdown of corn starch by thermal and mechanical effects. Carbohydrate Polymers, 56(4), 415-422.

van den Einde, R. M., Bolsius, A., van Soest, J. J. G., Janssen, L., van der Goot, A. J., \& Boom, R. M. (2004). The effect of thermomechanical treatment on starch breakdown and the 
Version définitive du manuscrit publiée dans / Final version of the manuscript published in :

Carbohydrate Polymers (2017), Vol. 177, p. 424-432, DOI: 10.1016/j.carbpol.2017.09.012

Journal homepage : http://www.elsevier.com/locate/carbpol

consequences for process design. Carbohydrate Polymers, 55(1), 57-63.

vanSoest, J. J. G., \& Vliegenthart, J. F. G. (1997). Crystallinity in starch plastics: Consequences for material properties. Trends in Biotechnology, 15(6), 208-213.

Wang, N., Zhang, X. X., Liu, H. H., \& He, B. Q. (2009). 1-Allyl-3-methylimidazolium chloride plasticized-corn starch as solid biopolymer electrolytes. Carbohydrate Polymers, 76(3), 482-484.

Xie, F. W., Flanagan, B. M., Li, M., Sangwan, P., Truss, R. W., Halley, P. J., et al. (2014). Characteristics of starch-based films plasticised by glycerol and by the ionic liquid 1-ethyl3-methylimidazolium acetate: A comparative study. Carbohydrate Polymers, 111, 841-848.

Xie, F. W., Flanagan, B. M., Li, M., Truss, R. W., Halley, P. J., Gidley, M. J., et al. (2015). Characteristics of starch-based films with different amylose plasticised by 1-ethyl-3- methylimidazolium acetate contents. Carbohydrate Polymers, 122, 160-168.

Zdanowicz, M., \& Johansson, C. (2016). Mechanical and barrier properties of starch-based films plasticized with two- or three component deep eutectic solvents. Carbohydrate Polymers, 151, 103-112.

Zdanowicz, M., \& Spychaj, T. (2011). Ionic liquids as starch plasticizers or solvents. Polimery, 56(11-12), 861-864.

Zdanowicz, M., Spychaj, T., \& Maka, H. (2016). Imidazole-based deep eutectic solvents for starch dissolution and plasticization. Carbohydrate Polymers, 140, 416-423.

Zhang, B. J., Xie, F. W., Zhang, T. L., Chen, L., Li, X. X., Truss, R. W., et al. (2016). Different characteristic effects of ageing on starch-based films plasticised by 1-ethyl-3-methylimidazolium acetate and by glycerol. Carbohydrate Polymers, 146, 67-79. 